\title{
DIE METING VAN MIDDELOORFUNKSIE VAN DIE NORMALE MENSLIKE OOR: 'N TIMPANOMETRIESE ONDERSOEK
}

\author{
I. S. HAY, M.A. (AUD.) (WASH.) \\ Departement Spraakwetenskap, Spraakheelkunde en Oudiologie, \\ Universiteit van Pretoria
}

\section{OPSOMMING}

Negeen-veertig normaalhorende proefpersone ( 96 ore) is onderwerp aan 'n timpanometriese ondersoek met 'n Grason-Stadler Otoadmittansmeter. Timpanogramme van konduktansie (G) en susseptansie (B) is gelyktydig geregistreer met meetfrekwensie $220 \mathrm{~Hz}$ en daarna met $660 \mathrm{~Hz}$ en oorkanaal drukverandering is in 'n positiewe sowel as negatiewe rigting toegepas. Sodoende is vir elke oor 8 timpanogramme verkry waarvan die statiese G- en B-waardes bereken is. Statiese admittansie ( $Y$ ) en impedansie $(Z)$ is volgens die standaardmetode bereken asook die fasehoek $(\emptyset)$. Die resultate het getoon dat enige van die G-en B-timpanogramme gebruik kan word vir die bepaling van middeloordruk. Die rigting van die drukverandering het verskille by indiwiduele ore opgelewer, maar geen betekenisvolle verskille ten opsigte van die gemiddelde waardes nie.

Die vorm van die timpanogramme bewys dat vals positiewe resultate veral by $660 \mathrm{~Hz}$ moontlik is aangesien normale ore 'n redelike mate van tipe D-timpanogramme openbaar. Die studie gee aanduidings van die moontlikheid dat timpanometrie o.a. by groot positiewe en negatiewe druk in die oorkanaal, inligting kan verskaf aangaande middeloorfunksie.

\section{SUMMARY}

Forty-nine normal hearing subjects (96 ears) were subjected to a tympanometric investigation using a Grason-Stadler Otoadmittance meter. Conductance $(G)$ and susceptance (B) tympanograms were recorded simultaneously using probe-tone frequencies $220 \mathrm{~Hz}$ and $660 \mathrm{~Hz}$. Tympanograms were recorded with ear canal pressure variation in a positive and negative direction. This gave a total of eight tympanograms for each ear which were used to obtain static values for $G$ and $B$. From this data static admittance $(Y)$ and static impedance $(Z)$ and phase angle $(\phi)$ were calculated using the standard formulae.

The results indicated that any of the $G$ and $B$ tympanograms could be used for determining middle-ear pressure. The direction of pressure change gave slightly different values of middle-ear pressure for some individual ears but there was no significant difference across subjects. The shape of the tympanograms proved that false positives are possible, especially using the $660 \mathrm{~Hz}$ probe tone, since a considerable number of normal ears displayed type $\mathrm{D}$ tympanograms. This research provides indications that tympanometry could furnish information relating to middle-ear function when considering results at great positive and negative pressure levels.

Sedert Metz in 1946 die meting van sekere aspekte van die impedansie op normale en patologiese ore gepubliseer het, het verskeie publikasies van navorsers in Europa en die V.S.A. die lig gesien. Binne twee jaar na die publikasie in Amerika van die kliniese toepassing van timpanometrie in 1970 het timpanometrie 'n baie populêre kliniese tegniek geword. ${ }^{4}$ Vandag word die tegniek 
wêreldwyd toegepas en dit word beskou as redelik betroubaar en maklik uitvoerbaar.

In die meeste kommersieel-beskikbare apparaat word daar slegs gebruik gemaak. van een aspek van impedansie, $\mathrm{nl}$. die reaktiewe komponent en omdat die oor by $220 \mathrm{~Hz}$ styfheid beheerd is, word slegs die 'compliance' (omgekeerde van die styfheid) gemeet. Die reële komponent van impedansie (akoestiese weerstand) word as so laag beskou vir die menslike oor dat dit nie gemeet word nie. Metings deur Zwislocki en Feldman ${ }^{15}$ het egter bewys dat waardevolle inligting tog bekom word indien die weerstandskomponent ook gemeet word. Hierdie navorsers het egter in 1970 slegs impedansmetings gemaak en dit was eers in 1974 dat Feldman ${ }^{3}$ met behulp van die Grason-Stadler Otoadmittansmeter timpanometrie bestudeer het gebruikmakende van beide reële en reaktiewe komponente van admittansie (die omgekeerde van impedansie) beide by $220 \mathrm{~Hz}$ en $660 \mathrm{~Hz}$.

Die gebruik van hierdie lae en hoë frekwensies het reeds getoon dat die hoër frekwensies $(660 \mathrm{~Hz}$ of $800 \mathrm{~Hz}$ ) besonder gevoelig is vir oordrom-abnormaliteite. Alberti en Jerger ${ }^{1}$ het dit egter duidelik gestel dat geen addisionele in. ligting bekom word deur by $800 \mathrm{~Hz}$ te meet nie angesien die W-tipe timpanogram by feitlik alle soorte middeloorpatologieë voorkom by $800 \mathrm{~Hz}$. Hulle het egter net 'compliance' gemeet en het dus nie 'n geheelbeeld verkry soos Feldman ${ }^{3}$ nie.

Die doel van die huidige ondersoek was om (as deel van 'n reeks ondersoeke) die normale menslike oor te onderwerp aan timpanometriese ondersoeke met behulp van die Otoadmittansmeter terwyl die konduktansie en susseptansie gelyktydig gemeet word, om die beurt by $220 \mathrm{~Hz}$ en $660 \mathrm{~Hz}$. In 'n tweede fase van die reeks ondersoeke sal soortgelyke metings uitgevoer word op proefpersone met bewese middeloorpatologieë. Aangesien daar tot dusver slegs twee publikasies ${ }^{3}, 5$ in hierdie verband verskyn het, word hierdie navorsing as belangrik beskou.

\section{METODE}

\section{PROEFPERSONE}

As proefpersone het opgetree studente en personeel van die departement Spraakwetenskap, Spraakheelkunde en Oudiologie van die Universiteit van Pretoria. Proefpersone is geselekteer op grond van normale gehoor (gehoorpeil nie groter nie as $15 \mathrm{~dB}$ I S O by 250 tot $4000 \mathrm{~Hz}$ ) en normaal verklaar deur 'n otoloog. Nege-en-veertig proef persone (96 ore) is gebruik. Die ouderdomme het gewissel tussen 18 en 33 jaar met 'n gemiddelde ouderdom van 20 jaar 10 maande.

\section{APPARAAT}

Vir die meting van die twee komponente van die admittansie is gebruik gemaak van die Grason-Stadler Otoadmittansmeter Model 1720. Twee HewlettPackard Tipe 7035B X - Y registreerders is respektiewelik gekoppel aan die uitgange van die otoadmittansmeter sodat die twee komponente van die admittansie gelyktydig gemeet kon word. Horisontale beweging op die registreer- 
ders is bewerkstellig deur hulle te koppel aan die otoadmittansmeter se lugdruksisteem se uitgang wat vir hierdie doel beskikbaar is. Sodoende is beweging na regs verteenwoordigend van druktoename in 'n positiewe rigting en na links van druktoename in 'n negatiewe rigting.

Yking van alle apparaat het daagliks geskied volgens voorskrifte van die vervaardigers. Korreksies vir hoogte bo seespieël en temperatuur is aangebring op alle admittansiewaardes verkry.

\section{ONDERSOEKMETODE}

Metings met die otoadmittansmeter het 8 timpanogramme opgelewer. Vir elke oor wat getoets is, is 'n timpanogram vir akoestiese konduktansie, G, en akoestiese susseptansie gelyktydig verkry by beide $220 \mathrm{~Hz}$ en $660 \mathrm{~Hz}$, beide in die positiewe en negatiewe rigting van druk verandering. Metings is in beide rigtings uitgevoer ten einde vas te stel of daar betekenisvolle verskille na vore kom wat die vorm van die timpanogramme betref. Statiese waardes van $G$ en

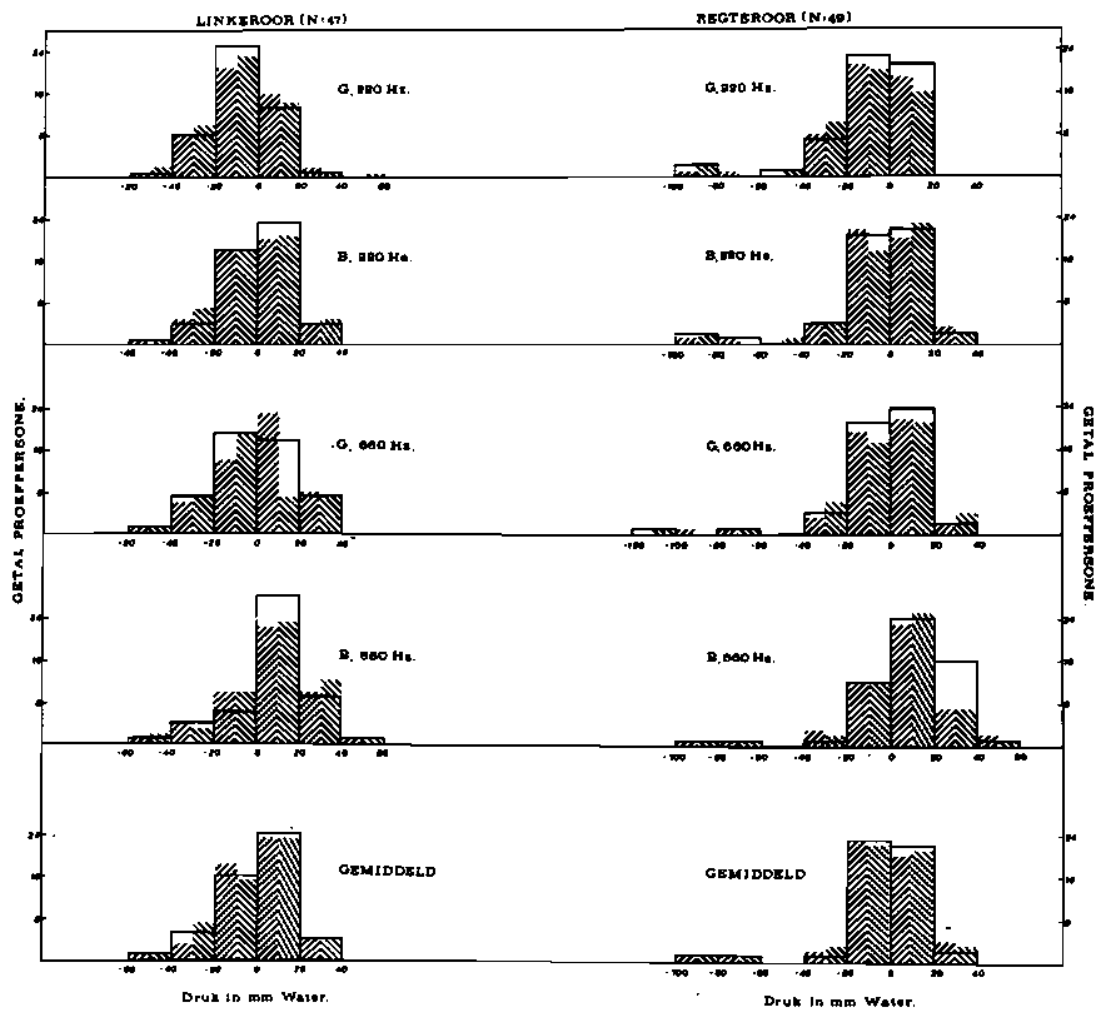

Figure 1. Verspreiding van middeloordruk as 'n funksie van meet frekwensie en admittanskomponente $G$ en $B$. "Y/, Dui aan timpanogram - drukverandering in rigting $-300 \mathrm{na}+300 \mathrm{~mm}$ water $\leqslant$ Dui aan drukverandering in rigting $+300 \mathrm{na}-300 \mathrm{~mm}$ water.

$G$ : Konduktansie. B: Susseptansie. 
$B$ is gebruik vir die berekening van die komplekse admittansie $Y$ deur middel van die formule $Y^{2}=G^{2}+B^{2}$. Die akoestiese impedansie, $Z$, is bepaal deur die formule $Z=\frac{1}{Y}$ te gebruik. Die fasehoek, $\phi$, is bepaal deur die formule $\phi=\tan ^{-1} \frac{B}{G}$ te gebruik.

\section{RESULTATE}

\section{MIDDELOORDRUK}

Die verspreiding van die resultate van middeloordruk (die drukwaarde waar die timpanogram se piek voorkom) word vir die linker- en regteroor vir al die meettoestande en rigting van drukverandering op Fig. 1 voorgestel. Vir al die toestande het meer as $80 \%$ van die metings tussen -20 en +20 mm waterdruk geval.

Gemiddelde middeloordrukwaardes vir die verskillende meettoestande en rig. ting van drukverandering word in Tabel I aangegee. Die laaste kolomme gee die algehele gemiddeldes en hiervan kan afgelei word dat die gemiddeldes vir beide ore feitlik $0 \mathrm{~mm}$ waterdruk is. Die feit dat die linkeroor se gemiddelde drukwaarde positief is en die regteroor s'n negatief, is hier van minder belang ondat beide waardes so klein is.

\begin{tabular}{|c|c|c|c|c|c|}
\hline \multirow[b]{3}{*}{$\begin{array}{l}\text { Rigting van druk- } \\
\text { verandering }\end{array}$} & \multicolumn{5}{|c|}{. } \\
\hline & \multicolumn{5}{|c|}{ Linkeroor $(N=47)$} \\
\hline & G $220 \mathrm{~Hz}$ & $\mathrm{G} 660 \mathrm{~Hz}$ & B $220 \mathrm{~Hz}$ & B $660 \mathrm{~Hz}$ & Gemiddeld \\
\hline $\begin{array}{l}\text { Negatief na } \\
\text { positief }\end{array}$ & $\begin{array}{c}-4,91 \\
(-59 /+24)\end{array}$ & $\begin{array}{c}1,14 \\
(-46 /+27)\end{array}$ & $\begin{array}{c}0,70 \\
(-59 /+25)\end{array}$ & $\begin{array}{c}0,34 \\
(-46 /+50)\end{array}$ & $\begin{array}{c}-0,68 \\
(-59 /+50)\end{array}$ \\
\hline $\begin{array}{l}\text { Positief na } \\
\text { negatief }\end{array}$ & $\begin{array}{c}-8,36 \\
(-53 /+23)\end{array}$ & $\begin{array}{c}0,17 \\
(-54 /+30)\end{array}$ & $\begin{array}{c}0,87 \\
(-52 /+25)\end{array}$ & $\begin{array}{c}0,34 \\
(-53 /+47)\end{array}$ & $\begin{array}{c}-1,75 \\
(-54 /+47)\end{array}$ \\
\hline \multirow[t]{2}{*}{ Gemiddeld } & $\left(\begin{array}{c}-6,64 \\
(-56 /+20,5)\end{array}\right.$ & $\begin{array}{c}0,66 \\
(-50 /+27)\end{array}$ & $\mid \begin{array}{c}0,79 \\
(-55,5 /+25)\end{array}$ & $\left(\begin{array}{c}0,34 \\
(-49,5 /+30,5)\end{array}\right.$ & $\begin{array}{c}-1,215 \\
(-56 /+30,5)\end{array}$ \\
\hline & \multicolumn{5}{|c|}{ Regteroor $(N=49)$} \\
\hline $\begin{array}{l}\text { Negatief na } \\
\text { positief }\end{array}$ & $\begin{array}{c}-7,93 \\
(-100 /+19)\end{array}$ & $\begin{array}{c}-2,24 \\
(-100 /+29)\end{array}$ & $\begin{array}{c}-3,42 \\
(-100 /+33)\end{array}$ & $\begin{array}{c}6,71 \\
(-100 /+50)\end{array}$ & $\begin{array}{c}-1,72 \\
(-100 /+50)\end{array}$ \\
\hline $\begin{array}{l}\text { Positief na } \\
\text { negatief }\end{array}$ & $\left(\begin{array}{c}-11,49 \\
(-100 /+20)\end{array}\right.$ & $\begin{array}{c}-3,79 \\
(-103 /+36)\end{array}$ & $\mid \begin{array}{c}-5,88 \\
(-100 /+27)\end{array}$ & $\begin{array}{c}4,57 \\
(-94 /+46)\end{array}$ & $\begin{array}{c}-4,15 \\
(-103 /+46)\end{array}$ \\
\hline Gemiddeld & $\left(\begin{array}{c}-9,71 \\
(-100 /+17)\end{array}\right.$ & $(-101,5 /+25)$ & $\mid \begin{array}{c}-4,65 \\
(-100 /+30)\end{array}$ & $\begin{array}{c}5,64 \\
(-97 /+48)\end{array}$ & $\begin{array}{c}-2,94 \\
(-101,5 /+48)\end{array}$ \\
\hline
\end{tabular}

TABEL I Gemiddelde middeloordrukwaardes vir timpanogram-optekening van G $220 \mathrm{~Hz}, \mathrm{G} 660 \mathrm{~Hz}$, B $220 \mathrm{~Hz}$ en B $660 \mathrm{~Hz}$ vir drukverandering in beide rigtings. Die verspreiding word in hakies aangegee. 
Die rigting van drukverandering het skynbaar 'n geringe invloed op die middeloordrukwaardes uitgeoefen. In alle gevalle is die gemiddelde waarde 'n meer negatiewe of minder positiewe waarde as die rigting van drukverandering van positief na negatief was en andersom, vir die teenoorgestelde rigting van drukverandering. Vir indiwiduele proefpersone was dit nie altyd die geval nie. Hierdie verskille is egter so klein dat dit nie kliniese waarde kan hê nie.

Die groter verspreiding van die regteroor (Fig. 1 en Tabel I) is die gevolg van relatief groot negatiewe middeloordrukwaardes van twee proefpersone, nl. $-100 \mathrm{~mm}$-waterdruk vir proefpersoon $32 \mathrm{en}-80 \mathrm{~mm}$-waterdrik vir proefpersoon 40 . Beide proefpersone se oudiogramme was binne normale perke. Jerger ${ }^{6}$ beskou die normale perke as $\pm 50 \mathrm{~mm}$-waterdruk terwyl Bluestone (soos gemeld in Harford ${ }^{4}$ ) gevind het dat -50 mm-waterdruk kan dui op 'n abnormale middeloor.

\section{STATIESE ADMITTANS- EN IMPEDANSWAARDES}

Statiese konduktansie, G, en susseptansie, B, van die middeloor is verkry deur die verskil te bereken van die waardes vir die middeloor in die gespanne ( + of -300 mm-waterdruk) en die ontspanne (druk waar timpanogram ' $n$ piek vorm) toestande. Indien die G-en B-waardes by + en $-300 \mathrm{~mm}$-waterdruk verskil het, is die gemiddelde van die twee waardes geneem. Die hoogte van die piek is dus die statiese waarde. ${ }^{13}$ Daar bestaan 'n verskil van opinie oor wysheid van hierdie metode van meting en daar is navorsers wat verkies om die hoogte van die timpanogram te bepaal by atmosferiese druk aangesien hulle voel dat dit die waarde van $\mathrm{G}$ en $\mathrm{B}$ bepaal wat in die praktyk geld. ${ }^{7}$ By die meting van hierdie waardes op proefpersone met normale gehoor, soos in die huidige studie, is daar nie 'n groot verskil tussen die twee metings, nl. by die maksimum van die timpanogram of by atmosferiese druk nie.

Die gemiddelde waardes van G, B, Y, Z en $\phi$ word in Tabel II angegee.

Resultate gepubliseer deur Feldman ${ }^{3}$ en Jacobson et al. ${ }^{5}$ word in Tabel III saamgevat. 'n Vergelyking van hierdie resultate en dié van die huidige ondersoek toon dat laasgenoemde resultate heelwat hoër is. By nadere ondersoek blyk dit dat die metode wat Feldman ${ }^{3}$ gebruik het om die statiese G-en B-waardes te meet, verskil van dié van die huidige ondersoek se metode. Feldman het die G- en B-waardes by atmosferiese druk gemeet en nie by die piek van die timpanogram soos by hierdie ondersoek die geval was nie. Die verskil is veral opmerklik by $660 \mathrm{~Hz}$.

'n Groter ooreenkoms word egter gevind indien die impedans-waardes van die huidige ondersoek vergelyk word met die resultate van $\mathrm{Zwislocki}$ en Feldman soos gemeld in Lilly ${ }^{10}$ en dié van Feldman ${ }^{3}$ soos aangedui in Tabel IV. Die ooreenstemming is hier merkwaardig. Die relatief klein verskil in meetfrekwensie kan geignoreer word. 


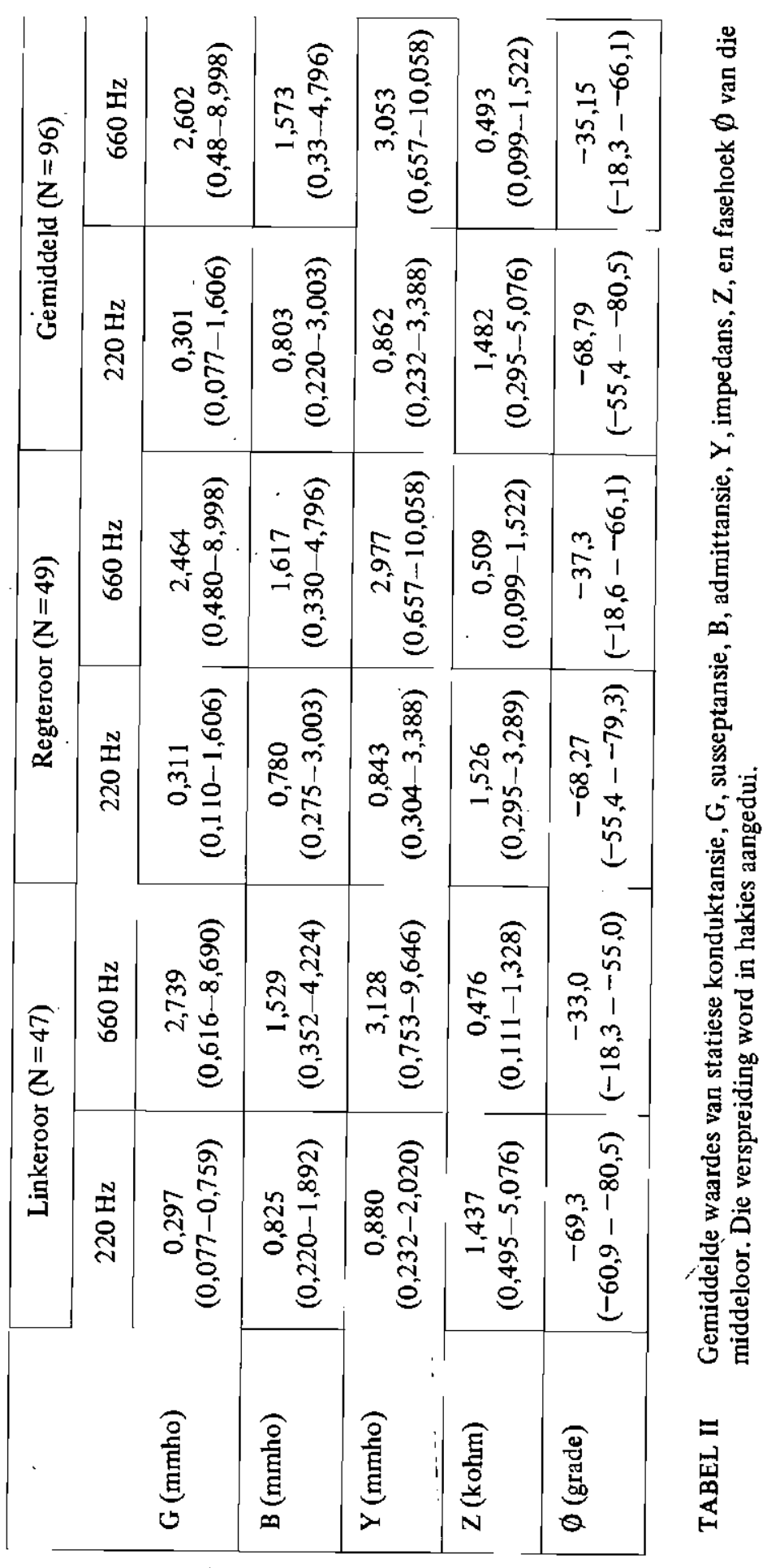

The South African Joumal of Communication Disorders, Vol. 24, 1977 


\begin{tabular}{|c|c|c|c|c|c|c|}
\hline \multirow{2}{*}{} & \multicolumn{2}{|c|}{ Jacobson et al. $^{5}(\mathrm{~N}=60)$} & \multicolumn{2}{c|}{ Feldman $^{3}(\mathrm{~N}=100)$} & \multicolumn{2}{c|}{ Hay $(\mathrm{N}=96)$} \\
\cline { 2 - 3 } & $220 \mathrm{~Hz}$ & $660 \mathrm{~Hz}$ & $220 \mathrm{~Hz}$ & $660 \mathrm{~Hz}$ & $220 \mathrm{~Hz}$ & $660 \mathrm{~Hz}$ \\
\hline $\mathrm{G}$ (mmho) & 0,28 & 1,7 & 0,15 & 1,95 & 0,301 & 2,602 \\
\hline B (mmho) & 0,58 & 0,83 & 0,50 & 1,30 & 0,803 & 1,573 \\
\hline
\end{tabular}

TABEL III Gemiddelde wardes van konduktansie, $G$, en susse ptansie, B, vir normale ore

\begin{tabular}{|c|c|c|c|}
\hline \multicolumn{3}{|c|}{ Impedansie (akoest. ohm) } \\
\hline Frekwensie & Zwislocki \& Feldman $^{15}$ & Feldman & Hay \\
& $(\mathrm{N}=66)$ & $(\mathrm{N}=100)$ & $(\mathrm{N}=96)$ \\
\hline $20 / 250 \mathrm{~Hz}$ & $1530 /-74,1^{\circ}$ & $1856 /-69,5^{\circ}$ & $1482 /-68,8^{\circ}$ \\
$660 / 750 \mathrm{~Hz}$ & $521 /-41,6^{\circ}$ & $409 /-31,0^{\circ}$ & $439 /-35,2$ \\
\hline
\end{tabular}

TABEL IV Gemiddelde impedanswaardes vir normale ore

\section{DIE VORM VAN DIE TIMPANOGRAM}

Afleidings word van die vorm van die timpanogram gemaak met die oog op die diagnose van middeloorpatologie. In hierdie ondersoek is slegs normaalhorendes gebruik om te poog om normatiewe waardes vas te stel. Die variasie wat die vorm van die timpanogram betref, is egter so groot dat feitlik alle vorms wat by verskillende patologieë voorgekom het, waargeneem is. Hiervan kan afgelei word dat daar ook vir die normale oor toestande bestaan wat timpanogramme lewer met vorms wat foutiewe diagnoses moontlik maak.

Tabel V gee die klassifikasie (volgens Jerger, ${ }^{6}$ Liden et al. ${ }^{8},{ }^{9}$ ) van die timpanogramvorms wat in hierdie studie verkry is. Die getalle dui op die aantal ore wat binne elke kategorie val. Die resultate dui daarop dat vir beide $G$ en $B$ by $220 \mathrm{~Hz}$ byna $80 \%$ van die timpanogramme 'n A-konfigurasie het. Verhoging van die meetfrekwensie na $660 \mathrm{~Hz}$ gee vir $\mathrm{G}$ 'n toename in die aantal ore wat timpanogramme van die $A_{D}$-konfigurasie het, d.w.s. 'n meer gedempte sisteem.

Die effek van frekwensieverhoging op B-timpanogramme, is die toename in die aantal ore met D- en E-konfigurasie. Hierdie konfigurasie word verklaar deur Liden et al. ${ }^{9}$ deur te verwys na die feit dat $660 \mathrm{~Hz}$ nader aan die resonansfrekwensie van die middeloor is en dat die susseptansie daar hoog is sodat met die oorgang van positiewe na negatiewe druk, die trommelvlies vinnig heen en weer beweeg. 'n Ander siening is die van Harford, ${ }^{4}$ nl. dat die D-konfigurasie moontlik die gevolg is van 'n losgekoppelde incudostapediale gewrig sodat verandering in die kanaaldruk om en by atmosferiese druk tot gevolg kan hê, 'n gedeeltelike ontkoppeling van die benige ketting. Liden et al. ${ }^{9}$ het gevind dat $8 \%$ van die 182 proefpersone met normale gehoor, tipe D-timpanogramme gelewer het, en hierdie resultaat word bevestig deur hierdie ondersoek (kyk tabel V, B $220 \mathrm{~Hz}$ ). Vir G $660 \mathrm{~Hz}$ en B $660 \mathrm{~Hz}$ word tipe D-timpanogram in $13 \%$ en $26 \%$ respektiewelik verkry. Liden et al. ${ }^{9}$ verbind tipe D met littekens op die trommelvlies. 


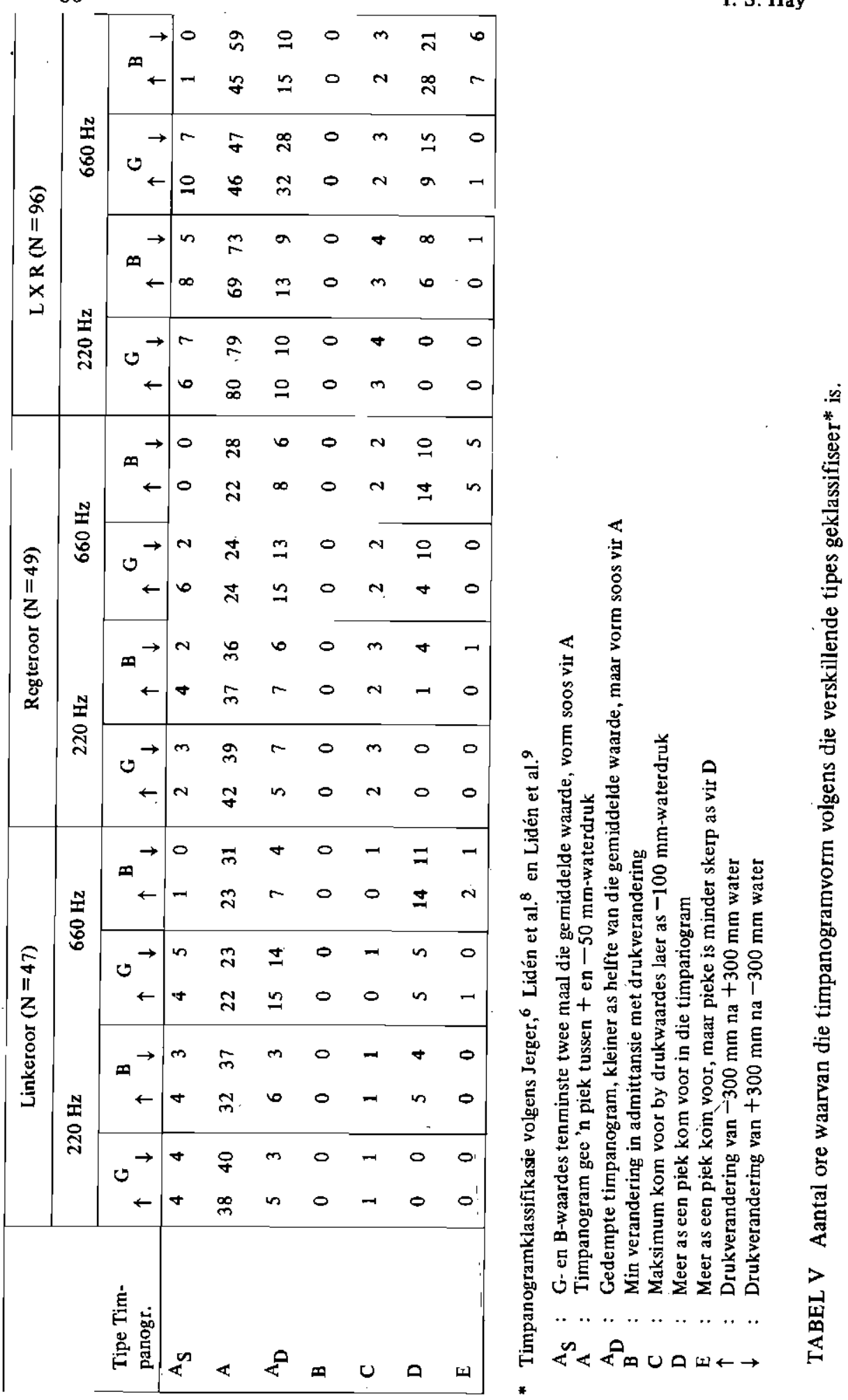


Die implikasies van bogenoemde resultate, is dat foutiewe diagnoses gemaak kan word deur tipe D-timpanogramme te koppel aan dislokasie van die benige ketting, veral by 'n meetfrekwensie van $660 \mathrm{~Hz}$. Hierdie feit word verder gestaaf deur die werk van Van Huyse et al. ${ }^{14}$ wat 'n wiskundige verklaring voorlê vir die $\mathrm{M}$ - of $\mathrm{W}$-patroon. Volgens hulle kom die patroon voor wanneer daar die regte kombinasie van druk, admittansie en frekwensie bestaan:

Timpanogram tipe $A_{S}$ kom wel voor by alle toestande, maar veral by $\mathrm{G} 220 \mathrm{~Hz}$, B $220 \mathrm{~Hz}$ en G $660 \mathrm{~Hz}$. Slegs een oor het 'n tipe A-timpanogram gegee by B $660 \mathrm{~Hz}$, maar daar moet gemeld word dat by hierdie toestand ongeveer 26 ore tipe $\mathrm{D}$ gegee het waaronder ingesluit was timpanogramme met pieke wat vergelykbaar was met tipe $\mathrm{A}_{\mathrm{S}}$.

Timpanogram tipe $B$ is nêrens waargeneem nie, hoewel heelwat van die $A_{D^{-}}$ tipes timpanogramme baie plat verloop het met'n geringe piek of hoogtepunt.

Timpanogram tipe $\mathrm{C}$ het wel in enkele gevalle voorgekom (Tabel V) en in een geval met ' $n$ middeloordrukwaarde van minder as $-100 \mathrm{~mm} \mathrm{H}_{2} \mathrm{O}$. Hoewel al die ore deur 'n ONK-arts as normaal gesertifiseer is, kan daar tog 'n paar ore gewees het met 'n geringe disfunksie van die buis van Eustachius.

Ook wat tipe $\mathrm{E}$ betref, is enkele ore gevind met hierdie tipe timpanogram veral vir toestand B $660 \mathrm{~Hz}$. Hierdie tipe word deur Liden et al. ${ }^{9}$ gekoppel aan dislokasie van die benige ketting.

Die afleiding kan gemaak word dat timpanogramme van $\mathrm{G} 660 \mathrm{~Hz}$ en B $660 \mathrm{~Hz}$ meer vals positiewe resultate gaan oplewer as G $220 \mathrm{~Hz}$ en B $220 \mathrm{~Hz}^{4}$ Die timpanogram kan dus nie sonder meer gebruik word om middeloorpatologie aan te dui nie.

Beskouing van die korrelasie tussen die timpanogramtipe en die uiterste gevalle van absolute admittanswaarde (Tabel VI) gee 'n duidelike beeld van 'n verband tussen hierdie waarnemings. Die proefpersone met lae admittanswaardes het feitlik deurgaans 'n tipe $A_{2}$-(gedempte) timpanogram gegee, terwyl diegene met 'n hoë admittansie 'n tipe D-timpanogram opgelewer het. Hierdie korrelasie bestaan ook vir die konduktansie-en susseptansie-waardes.

\begin{tabular}{|c|c|c|c|c|}
\hline & Timpanogram-tipe & $\begin{array}{c}\text { Admittansie } \\
(220 \mathrm{~Hz})\end{array}$ & $\begin{array}{c}\text { Konduktansie } \\
(220 \mathrm{~Hz})\end{array}$ & $\begin{array}{c}\text { Susseptansie } \\
(220 \mathrm{~Hz})\end{array}$ \\
\hline Proefpersoon Nr. & (Linkeroor) & $(\mathrm{X}=, 860)$ & $(\overline{\mathrm{X}}=, 27)$ & $(\overline{\mathrm{X}}=, 74)$ \\
\hline 9 & $\mathrm{~A}_{2}$ &, 468 &, 17 &, 39 \\
11 & $\mathrm{~A}_{2}$ &, 404 &, 14 &, 34 \\
42 & $\mathrm{~A}_{2}$ &, 503 &, 20 &, 44 \\
35 & $\mathrm{~A}_{2}$ &, 232 &, 07 &, 20 \\
7 & $\mathrm{~A}_{2}$ &, 382 &, 11 &, 33 \\
15 & $\mathrm{D}$ & 1,768 &, 43 & 1,55 \\
30 & $\mathrm{D}$ & 1,571 &, 64 & 1,28 \\
37 & $\mathrm{D}$ & 1,785 &, 60 & 1,51 \\
41 & $\mathrm{D}$ & 2,020 &, 61 & 1,72 \\
& $\mathrm{D}$ & 1,817 &, 69 & 1,51 \\
\hline
\end{tabular}

TABEL VI Timpanogram-tipe en hoogste en laagste admittanswaardes by $220 \mathrm{~Hz}$ 
'n Verskynsel wat opmerklik was, was die verskil wat daar soms bestaan het, tussen die G-sowel as B-waardes by 'n druk van $-300 \mathrm{~mm}$ en $+300 \mathrm{~mm}$ $\mathrm{H}_{2} \mathrm{O}$. Dit word veronderstel dat beide hierdie druktoestande 'n harde wandholte skep wat 'n meting is van die ekwivalente volume gelyk aan die volume van die eksterne meatus met uitskakeling van die middeloor. ${ }^{4}$ Die rigting van die drukverandering het in die meeste gevalle nie verskil gemaak wat die G- en B-waardes by -300 en $+300 \mathrm{~mm} \mathrm{H}_{2} \mathrm{O}$-druk betref nie. Die verwagting was dat 'n positiewe druk in die oorkanaal groter G- of B-waardes tot gevolg sou hê aangesien die trommelvlies na binne geforseer word, maar dit was nie altyd die geval nie.

Tabel VII gee ' $n$ aanduiding van die aantal ore waar die verandering in $G$ en $B$ met druk kleiner was by $-300 \mathrm{~mm}$ as by $+300 \mathrm{~mm}$ water. Hieruit kan afgelei word dat vir $G 660 \mathrm{~Hz}$ was die verandering in $\mathrm{G}$ in $77 \%$ van die ore kleiner vir 'n druk van $-300 \mathrm{~mm}$ as vir $+300 \mathrm{~mm}$-waterdruk in die oorkanaal.

\begin{tabular}{|l|c|c|c|c|}
\hline \multirow{2}{*}{ Regteroor } & \multicolumn{4}{|c|}{ AANTAL ORE } \\
\cline { 3 - 5 } & G $220 \mathrm{~Hz}$ & B $220 \mathrm{~Hz}$ & G $660 \mathrm{~Hz}$ & B 660 Hz \\
\cline { 2 - 5 } & 1 & 6 & 42 & 1 \\
\hline Linkeroor & 6 & 1 & 35 & 0 \\
\hline Totaal & 7 & 7 & 77 & 1 \\
\hline
\end{tabular}

TABEL VIl Aantal ore waarvan die verandering in $G$ en $B$ kleiner was by ' $n$ oorkanaaldruk van $-300 \mathrm{~mm}$ as by ' $\mathrm{n}$ druk van $+300 \mathrm{~mm}$ waterdruk

By G 220, B 220 en B $660 \mathrm{~Hz}$ is daar slegs enkele ore gevind wat genoemde verskynsel openbaar, met ander woorde, in die meeste ore is die omgekeerde waar, nl. dat 'n groot positiewe druk in die oorkanaal ' $n$ kleiner verandering in $G$ en $B$ gee as'n groot negatiewe druk. Hierdie resultaat stem in 'n mate ooreen met metings wat deur McPherson et al. ${ }^{11}$ op marmotte uitgevoer is. Meting van middeloorimpedansie met veranderde middeloordruk, het getoon dat by $200 \mathrm{~Hz}$ en $+300 \mathrm{~mm}$-waterdruk in die middeloor, die impedansverandering groter is as by $-300 \mathrm{~mm}$-waterdruk. (Dit moet onthou word dat $+300 \mathrm{~mm}$ waterdruk in die middeloor soos deur McPherson gebruik, ooreenstem met $+300 \mathrm{~mm}$-waterdruk in die oorkanaal). McPherson et al. ${ }^{11}$ se resultaat by $200 \mathrm{~Hz}$ stem ooreen met die resultaat van hierdie ondersoek by $220 \mathrm{~Hz}$. Hul resultaat by $600 \mathrm{~Hz}$ gee dieselfde verandering in impedansie by $+300 \mathrm{~mm}$ - en $-300 \mathrm{~mm}$-waterdruk in die middeloor, terwyl daar in hierdie ondersoek gevind is dat vir $\mathrm{G} 660 \mathrm{~Hz}$, die verandering in admittansie groter is (vir $80 \%$ van die ore) vir $+300 \mathrm{~mm}$-waterdruk in die oorkanaal as vir $-300 \mathrm{ram}$-waterdruk. Hierdie toestand kom vir die marmot (volgens $\mathrm{McPherson}$ et al. ${ }^{11}$ ) alleen voor by hoë frekwensies, bv. by $10 \mathrm{KHz}$.

Die verskille by die maksimum positiewe en negatiewe druk, het waarskynlik te make met die verandering in die meganiese eienskappe van die middeloor 
wanneer die stelsel ver na binne of ver na buite geforseer word deur hoë druk. waardes. ${ }^{11}$ 'n Groot negatiewe druk in die eksterne oorkanaal het tot gevolg die gedeeltelike ontkoppeling van die incudostapediale gewrig (dus groter wrywing en kleiner $G$ ) tesame met 'n groter gèspannenheid van die trommelvlies en membraan van die ovale venster. 'n Groot positiewe druk in die eksterne oorkanaal vergroot die koppeling van die gewrig (groter $G$ ) en vergroot die gespannenheid van die membrane met 'n verdere moontlikheid dat die wyse van beweging van die stapes verander soos met groot klankdruk. ${ }^{2}$

\section{GEVOLGTREKKINGS}

Die doel van die studie was om 'n waardebepaling te maak van die waardes van konduktansie, G, en susseptansie, B, soos gemeet op proefpersone met gehoor binne normale perke. Verder moes daar vasgestel word of die rigting van drukverandering by die bepaling van die timpanogram van belang was en of die gebruik van $220 \mathrm{~Hz}$ sowel as $660 \mathrm{~Hz}$ as meetfrekwensie van waarde is by die bepaling van normale waardes.

Die volgende gevolgtrekkings kan gemaak word:

Die G, B, Y, Z en $\phi$ waardes in hierdie studie verkry stem in 'n groot mate ooreen met dié verkry in ander studies, ${ }^{3,5,15}$ hoewel daar toegelaat moet word vir die feit dat die plek op die timpanogram waar $G$ en $B$ gemeet is, verskil van hierdie studie. Wanneer daar by die piek gemeet word (soos in hierdie studie) is die waardes van $G$ en $B$ en dus $Y$ groter as wanneer die meting by atmosferiese druk gemaak word soos in die studies van Feldman ${ }^{3}$ en Jacobson et al..$^{5}$

Die meettoestand (G 220, G 660, B 220, B 660) en rigting van drukverandering in die oorkanaal het min invloed op die meting van middeloordruk. Daar was wel 'n opmerklike verskil by indiwiduele proefpersone, maar nie sodanig dat dit diagnosties van betekenis sou wees nie. Dit is miskien te verwagte dat 'n meganiese stelsel soos die middeloor effens gevoelig sal wees vir die rigting van drukverandering in die oorkanaal veral by die drukwaardes waar optimum beweeglikheid verkry word. Ook by die bepaling van $\mathrm{G}$ en $\mathrm{B}$ het die rigting van die drukverandering in die oorkanaal geen noemenswaardige invloed gehad nie.

Die vorm van die timpanogram wat aanduidend is van die beweeglikheid van die middeloor bevat by die normale oor tipes van feitlik al die tipes wat verteenwoordigend is van sekere middeloorpatologieë. Die gebruik van die vorm van die timpanogram vir diagnostiese doeleindes moet dus baie versigtig geskied. Feldman ${ }^{3}$ waarsku ook hierteen en meld dat 'n trommelvlies met geneesde perforasies ' $n$ beeld kan gee van 'n baie beweeglike sisteem wat die teenwoordigheid van otosklerose kan verbloem.

Die gebruik van beide die $220 \mathrm{~Hz}$ en die $660 \mathrm{~Hz}$ meettoon is veral van waarde wat die vorm van die timpanogram betref. Ook hier moet egter 'n waarskuwing gerig word wat die gebruik van hierdie inligting vir diagnostiese doeleindes betref aangesien die voorkoms van tipe $\mathrm{D}$ (M- of W-patroon) by proefpersone met normale gehoor redelik aansienlik is (26\% van 100 normale ore by B. $660 \mathrm{~Hz}$ 
en $13 \%$ by $\mathrm{G} 660$ ). Die toestand $\mathrm{G} 220 \mathrm{~Hz}$ blyk meer betroubaar te wees omdat dit die hoogste persentasie (84\%) as tipe A gediagnoseer het en die laagste persentasie (O\%) as tipe D. Die toestand B $660 \mathrm{~Hz}$ het die laagste persentasie (56\%) as tipe A gediagnoseer en die hoogste persentasie (26\%) as tipe D. Hieruit kan afgelei word dat daar wel met voordeel van die gebruik van G. timpanogramme gebruik gemaak kan word.

Die timpanogramme van G $220 \mathrm{~Hz}, \mathrm{~B} 220 \mathrm{~Hz}, \mathrm{G} 660 \mathrm{~Hz}$ en B $660 \mathrm{~Hz}$ gee gesamentlik ' $n$ beeld van die middeloorfunksie wat nie moontlik is met slegs $B$. $220 \mathrm{~Hz}$ en B $660 \mathrm{~Hz}$ timpanogramme wat gewoonlik met kommersieel-beskikbare, apparaat geregistreer word nie. Afleidings wat gemaak kan word van die G- en B-waardes met die oordrom in die gespanne toestand ( $\pm 300 \mathrm{~mm}$ waterdruk) kan moontlik van diagnostiese waarde wees, maar hierdie aspek moet verder ondersoek word.

\section{VERWYSINGS}

1. Alberti, P. W. R., Jerger, J. (1974): Probe tone frequency and the diagnostic value of tympanometry. Arch. Otolaryngol., 99, 3, 206-210.

2. Bekesy, G. Von, (1960): Experiments in Hearing. McGraw Hill, New York.

3. Feldman, A. S., (1974): Eardrum abnormality and the measurement of middle ear function. Arch Otolaryngol., 99, 211-217.

4. Harford, E. R., (1975): Tympanometry. In Handbook of Clinical Impedance, Jerge:, J. (Ed.). American Medics Corp., New York.

5. Jacobson, J. T., Kimmel, B. L., en Fausti, S. A., (1975): Clinical Application of the Grason-Stadler Oto-admittance meter. Asha, 1, 11-16.

6. Jerger, J. (1970): Clinical experience with Impedance Audiometry. Arch. Otolaryngol., 92, 311-324.

7. Jerger, J. (1976): Suggested nomenclature for impedance audiometry. In Selected Readings in Impedance Audiometry. Northern, J. L. (Ed.). American Medics Corp., New York.

8. Lidén, G., Petersen, J. L., Bjorkman, G. (1970): Tympanometry , Arch. Otolaryngol., 92, 248-257.

9. Lidén, G., Harford, E., Hallen, O. (1974): Automatic Audiometry in Clinical Practice. Audiology, 13, 126.139.

10. Lilly, D. J. (1972): Acoustic Impedance at the Tympanic Membrane. In Handbook of Clinical Audiology. Katz, J. (Ed.). Baltimore, Wílliams \& Wilkins Co.

11. McPherson, D. L., Miller, J. M., Axelsson, A. (1976): Middle ear pressure: Effects on the auditory periphery.J. Acoust. Soc. Amer., 59, 135-142.

12. Miller, J. M., Holmquist, J. (1974): An animal model for study of Eustachian tube and middle ear function.:Scand. Audiol., 3, 63-68.

13. Northern, J. L. (1975): Clinical Measurement procedures. In Handbook of Clinical Impedance Audiometry. Jerger, J. (Ed.). American Medics Corp., New York. 
14. Van Huyse, V. J., Creten, W. L., Van Kamp, K. J. (1975): On the W-notching of tympanograms. Scand. Audiol., 4, 45-50.

15. Zwislocki, J., Feldman, A. S. (1970): Acoustic Impedance of Pathological Ears. Amer. Sp. Hear. Assoc., Monogr. No. 15.

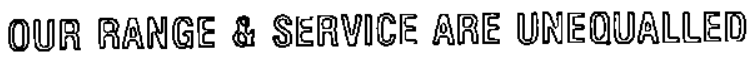
for

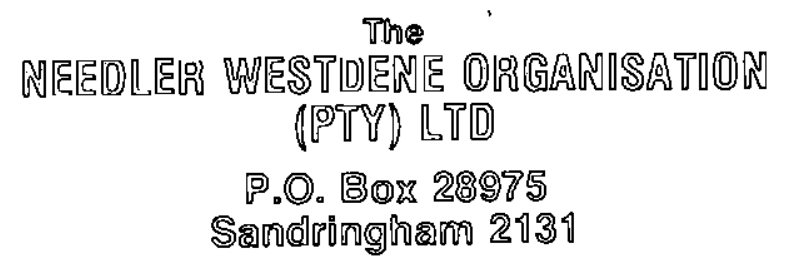

Telephones: 45-7262 


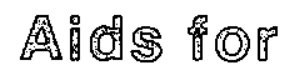
(2) the development of perception
(3) the acquisition of speech and lan- guage skills
(2) the improvement of motor co-ordination

Plus.
(2) helpful texts for therapists
2.3 educational toys, books and equip- ment
7ecords for auditory training
catalogues on request
- large variety of tests available

\section{Comst绝}

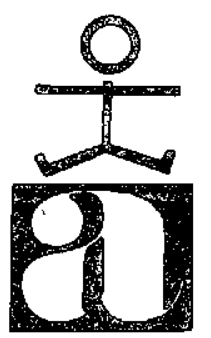

PLAY ANLE SCHOOLROOM

8 Tyrwhitt Avenue, Rosebank (adjoining the Constantia Cinema)

Telephones: 788-1304

P.O. Box 52137, Saxonwold, Tvl. 